\title{
MACRO-MICROSCOPICAL ANATOMY OF THE GIZZARD OF EGYPTIAN LAUGHING DOVE AND ROCK PIGEON
}

\author{
FATMA A. MADKOUR and ALSAYED A. MOHAMED \\ Department of Anatomy and Embryology, Faculty of Veterinary Medicine, South Valley \\ University, Qena 83523, Egypt. Telefax/+20965211223
}

Received: 12 March 2019; Accepted: 30 April 2019

\begin{abstract}
This study aimed to maximize the acquaintance on the morphology of the gizzard of the Laughing Dove (LD) and Rock Pigeon (RP). Gizzards of ten birds of each species were used for gross anatomy, scanning electron microscope and light microscope. The gizzard was biconvex lens in shape with rhomboidal circumference in both birds and with more oval in LD. The gizzard length constituted $55.41 \%$ in LD and $53.60 \%$ in RP of the total length of the stomach. The gizzard extended from the level of the $5^{\text {th }}$ intercostal space to terminat $12.25 \pm 1.18$, $17.27 \pm 0.88 \mathrm{~mm}$ behind the last rib and $10.90 \pm 0.70,19.48 \pm 0.49 \mathrm{~mm}$ infront of the vent in LD and RP respectively. The midway section through the thick muscles in the dorsoventral plane parallel to the tendinous center showed that the gizzard lumen appeared nearly S-shaped at both birds with 2 invaginations at caudal end of the lumen toward the caudoventral blind sac of RP. Another midway section through the thick muscles and tendinous center in the dorsoventral plane explained that the gizzard lumen was nearly elliptical in RP and rectangular in LD surrounded in both sides by semi ellipsoid thick muscles. By SEM, the cutical folds of the gizzard resembled bundles of rods in LD and appeared as group of blunt projections in RP. The epithelial lining of the tubular glands was columnar with large rounded or oval nuclei and deeply stained basophilic cytoplasm.
\end{abstract}

Key words: Laughing dove, Rock pigeon, Gizzard, SEM, Histology.

\section{INTRODUCTION}

Both RP and LD belong to the same bird family Columbidae. LDs feed on seeds, grasses, other vegetable matter and small ground insects such as termites and beetles (Satheesan et al., 1990, Adang et al., 2008). LD is becoming very domesticated in Africa, the Middle East and the Indian Subcontinent (Ali and Ripley, 1981). The habitat of RP is restricted in western and southern Europe, North Africa, and South Asia (Gibbs et al., 2010). There are three types of birds according to their stomachs; first type; birds eating on soft food in which the function of the gizzard is the stock piling of food. Second type; birds eating on hard diet in which the gizzard is performed mechanical treatment of the food while the third type; birds eating on intermediate diet in which the role of gizzard is storage and physical digestion (Hassouna, 2001). The relative size of the gizzard is greatest in seedeating or plant-eating birds (Evans, 1996). In granivores and herbivores birds, the gizzard is subdivided into three portions including cranial sac, caudal sac and body (McLelland, 1979). The gizzard

Corresponding author: Dr. FATMA A. MADKOUR

E-mail address: madkour.fatma@yahoo.com: madkour.f@vet.svu.edu.eg

Present address: Department of Anatomy and Embryology, Faculty of Veterinary Medicine, South Valley University, Qena 83523, Egypt. in birds replaces the function of teeth in mammals. The cuticle aids the gizzard to break down grains into smaller bits to become more readily digested by the gastric enzymes and also stones (grit) that presented normally in the gizzards which grinding of grains and as a source of trace minerals (Heath and Olusanya, 1985). The cuticle protects the muscular stomach from degrading effects of the gastric acids and mechanical action of foods particles secreted by the tubular glands of gizzard (Gussekloo, 2006). The studies on the Egyptian LD and RP were scarce so our work provided more information on the morphological features and morphometric data of the gizzard and discussion the current findings with antecedent data from other birds.

\section{MATERIALS AND METHODS}

Ten adult birds of each Egyptian LDs and RPs were used in this study which restricted alive by a local owner in Qena governorate, Egypt, who is a registered member of the Egypt union for pigeon's race. The mean weight of LD was $94.26 \pm 8.02 \mathrm{gm}$ and that of RP was $294.12 \pm 16.18 \mathrm{gm}$. The mean length of the body cavity (from thoracic inlet to cloaca) was $58.87 \pm 1.05 \mathrm{~mm}$ in $\mathrm{LD}$ and $82.02 \pm 2.89$ $\mathrm{mm}$ in RP. The birds were anesthetized by chloroform, slaughtered and then completely bled. The position and relations of the gizzard were inspected in situ following a mid-ventral incision. 
The morphometric results of the gizzards were recorded by using a digital caliper after cleaning by saline and fixed in 10\% neutral buffered formalin. For SEM, the samples of the gizzards were collected, fixed and dehydrated using different grades of alcohol and finally critical point dried. The dried samples were mounted on the stubs, gold coated and finally viewed and photographed using JEOL scanning electron microscopy (JSM-5400). For the light microscopical examination, the samples dehydrated in ascending grades of alcohol (70$100 \%$ ) after proper fixation, the samples subjected to methyl benzoate for clearances and then embedded in paraffin wax. The paraffin-embedded samples were sectioned at $3-5 \mu \mathrm{m}$ thickness stained by Hematoxylin \& Eosin stain (Harris, 1898) and Crossman's trichrome stain (Crossman, 1937). The microscopical morphometry of the gizzard was performed for each bird using Image $\mathbf{J}$ software. For resin embedding samples, small specimens measured 2.0-3.0 $\mathrm{mm}$ from the gizzard were used in semithin sections. They were fixed in $2.5 \%$ glutaraldehyde and $4 \%$ paraformaldehyde at $4{ }^{\circ} \mathrm{C}$ for 3 days; post fixed in osmium tetraoxide $1 \%$, dehydrated in ascending grades of acetone then embedded in spur's resin. Semithin sections $(0.5 \mu \mathrm{m}$ thickness) were cut then stained with toluidine blue and finally examined by light microscope (Bancroft et al., 2013).

\section{RESULTS}

The stomach consisted of two distinct parts small cranial part; proventriculus (Pars glandularis) and a large caudal part; gizzard (Pars muscularis or ventriculus). The length of the stomach was $34.27 \pm 0.85 \mathrm{~mm}$ in $\mathrm{LD}$ and $46.66 \pm 1.30 \mathrm{~mm}$ in RP. The weight of the stomach was $2.90 \pm 0.21 \mathrm{gm}$ in LD and 7.16 $\pm 0.20 \mathrm{gm}$ in RP. The gizzard was biconvex lens in shape with rhomboidal circumference in the both birds and with more oval in LD. It consisted of body and 2 blind sacs; craniodorsal and caudoventral blind sacs. The proventriculus opened into the cranial aspect of the craniodorsal blind sac through isthmus and the duodenum exited from the cranial part of the right surface of the gizzard through pyloric opening (Fig. 1). The gizzard extended from the level of the $5^{\text {th }}$ intercostal space to terminat $12.25 \pm 1.18,17.27 \pm 0.88 \mathrm{~mm}$ behind the last rib and $10.90 \pm 0.70,19.48 \pm 0.49 \mathrm{~mm}$ infront of the vent in LD and RP respectively.

The cranial end of the gizzard contacted with the caudal end of the left lobe of the liver forming deep impression, but the caudal end was related to the duodenum and pancreas. The dorsal surface was related to the testis in male and ovary in female in addition to the left abdominal air sac, while the ventral surface was completely related to the abdominal floor in LD and partially related to the ventral part of the visceral surface of the right lobe of the liver in RP. The left surface was related to the left abdominal wall and left abdominal air sac, while the right surface was related cranially to the spleen and visceral surface of the right lobe of the liver forming deep impression and the remaining part of the right surface of the gizzard was related to the jejunum and duodenum (Fig. 1).

From the statistical data of this work; the length of the gizzard of LD $(18.99 \pm 0.53 \mathrm{~mm})$ was shorter than that of RP $(25.01 \pm 0.80 \mathrm{~mm})$. The gizzard length constituted $55.41 \%$ and $53.60 \%$ of the total length of the stomach and $32.25 \%$ and $30.49 \%$ of that of the body cavity in LD and RP respectively. For the weight of the gizzard, it was $2.68 \pm 0.24 \mathrm{gm}$ in LD and $6.65 \pm 0.18 \mathrm{gm}$ in RP. The gizzard weight formed nearly the same percentage to the weight of the stomach. This percentage was $92.41 \%$ in LD and $92.87 \%$ in RP. Moreover, the gizzard width and height in LD were less than those of RP which recorded $11.12 \pm 0.38,21.19 \pm 0.38 \mathrm{~mm}$ in $\mathrm{LD}$ and $15.41 \pm 0.17,27.99 \pm 0.13 \mathrm{~mm}$ in RP respectively.

The gizzard wall consisted of 2 lateral thick muscles of the body (caudodorsal and cranioventral) and 2 intermediate thin muscles of the blind sacs (craniodorsal and caudoventral) (Figs. 1\&2). Internally, midway section through the thick muscles in the dorsoventral plane parallel to the tendinous center showed that the caudodorsal thick muscle conjoined cranially with the craniodorsal thin muscle and the cranioventral thick muscle conjoined caudally with the caudoventral thin muscle (Fig. 2). In this section, the gizzard lumen appeared nearly Sshaped in both birds with 2 invaginations observed at the caudal end of the lumen toward the caudoventral blind sac of RP (Fig. 2). The length of the gizzard lumen of LD $(17.89 \pm 1.37 \mathrm{~mm})$ was shorter than that of RP $(25.56 \pm 0.23 \mathrm{~mm})$. While the diameter at the widest part was nearly similar in both birds, it was $9.58 \pm 0.31$ and $9.54 \pm 0.53 \mathrm{~mm}$ in LD and RP respectively. Another midway section through the thick muscles and tendinous center in the dorsoventral plane explained that the gizzard lumen was nearly elliptical in RP and rectangular in LD surrounded in both sides by semiellipsoid thick muscles. The edge of this lumen was more wrinkled toward thick muscles than that toward the tendinous center (Fig. 2). The inner aspect of the gizzard was lined by a hardened membrane (cuticula gastrica). The thickness of the cuticle was variable in body and blind sacs. The cuticle at the blind sacs was very thin so difficult to be measured. However, the cuticle thickness at the body was nearly similar in both birds; it recorded $0.96 \pm 0.53 \mathrm{~mm}$ in LD and $0.91 \mathrm{~mm} \pm 0.53$ in RP.

By SEM, the gizzard composed of cuticle, mucosa, submucosa, muscular layers. The tunica mucosa contained many tubular glands closely attached to the cuticle. At higher magnification, the cuticle 
consisted of 2 layers; vertical rods and horizontal matrix. The cutical folds resembled bundles of rods in LD and appeared as group of blunt projections in RP. These folds separated by deep grooves (Fig. 3).

By light microscope, the thickness of the gizzard mucosa measured $482.87 \pm 20.87 \mu \mathrm{m}$ in LD and $527.85 \pm 47.32 \mu \mathrm{m}$ in RP; it consisted of lamina epithelialis and lamina propria. The lamina epithelialis invaginated toward the lamina propria forming gizzard tubular glands. The lining epithelium of the tubular glands was cuboidal cells with rounded nuclei and basophilic cytoplasm (at top cells showed dark nucleus). The epithelial mucosa covered by cuticle; its layers (vertical rods and horizontal matrix) had same intensity. The lamina propria consisted of loose connective tissue occupied by simple tubular glands extended to submucosa. The length of the gizzard tubular glands of LD $(282.62 \pm 26.05 \mu \mathrm{m})$ was less than that of RP $(377.07 \pm 40.93 \mu \mathrm{m})$ by nearly one and a half fold. Semithin sections stained with toluidine blue exhibited that the epithelial lining of the tubular glands was columnar with large rounded or oval nuclei and deeply stained basophilic cytoplasm. The cuticula gastrica and secretion within the lumen of the tubular glands stained red with Crossman's trichrome technique. The submucosa was well developed consisted of connective tissue contained blood vessels and ganglionic cells extended between tubular glands of the mucosa. The muscular layer of the gizzard consisted of circulatory arranged smooth muscle fibers. The muscular bundles were separated by connective tissue septa (Fig. 4).

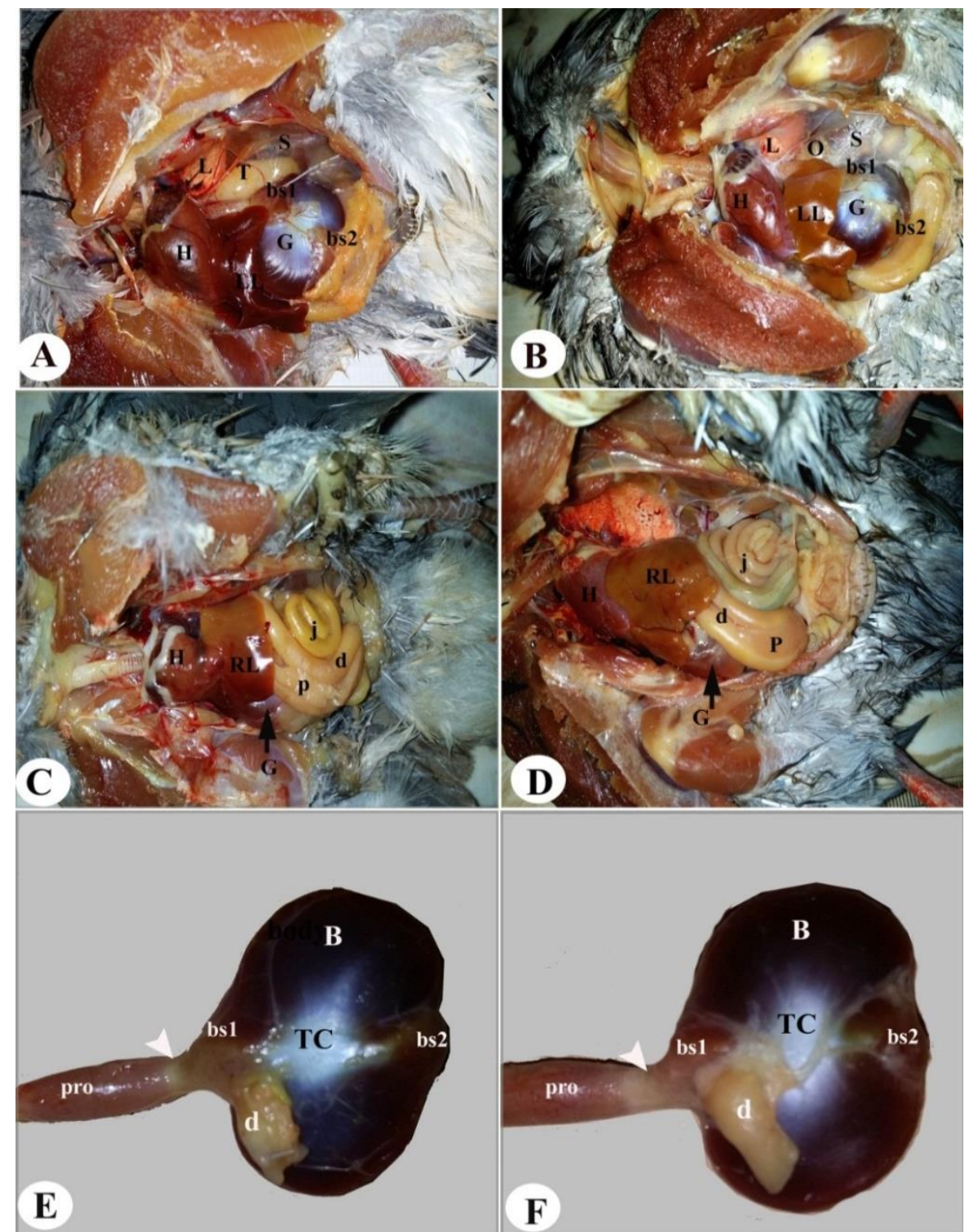

Fig.1: Photographs of the left side (A) \& (B) and of the right side (C) \& (D) of the body cavity and the right surface of the gizzard (E) \& (F) of laughing dove and rock pigeon respectively. Note, heart (H), gizzard (G), left lobe (LL) \& right lobe (RL) of liver, lung (L), testes (T), jejunum (j), duodenum (d), pancreas (p), abdominal air sac (S), body of gizzard (B), craniodorsal (bs1) \& caudoventral (bs2) blind sacs, tendentious center (TC), proventriculus (pro), isthmus (arrow head). 

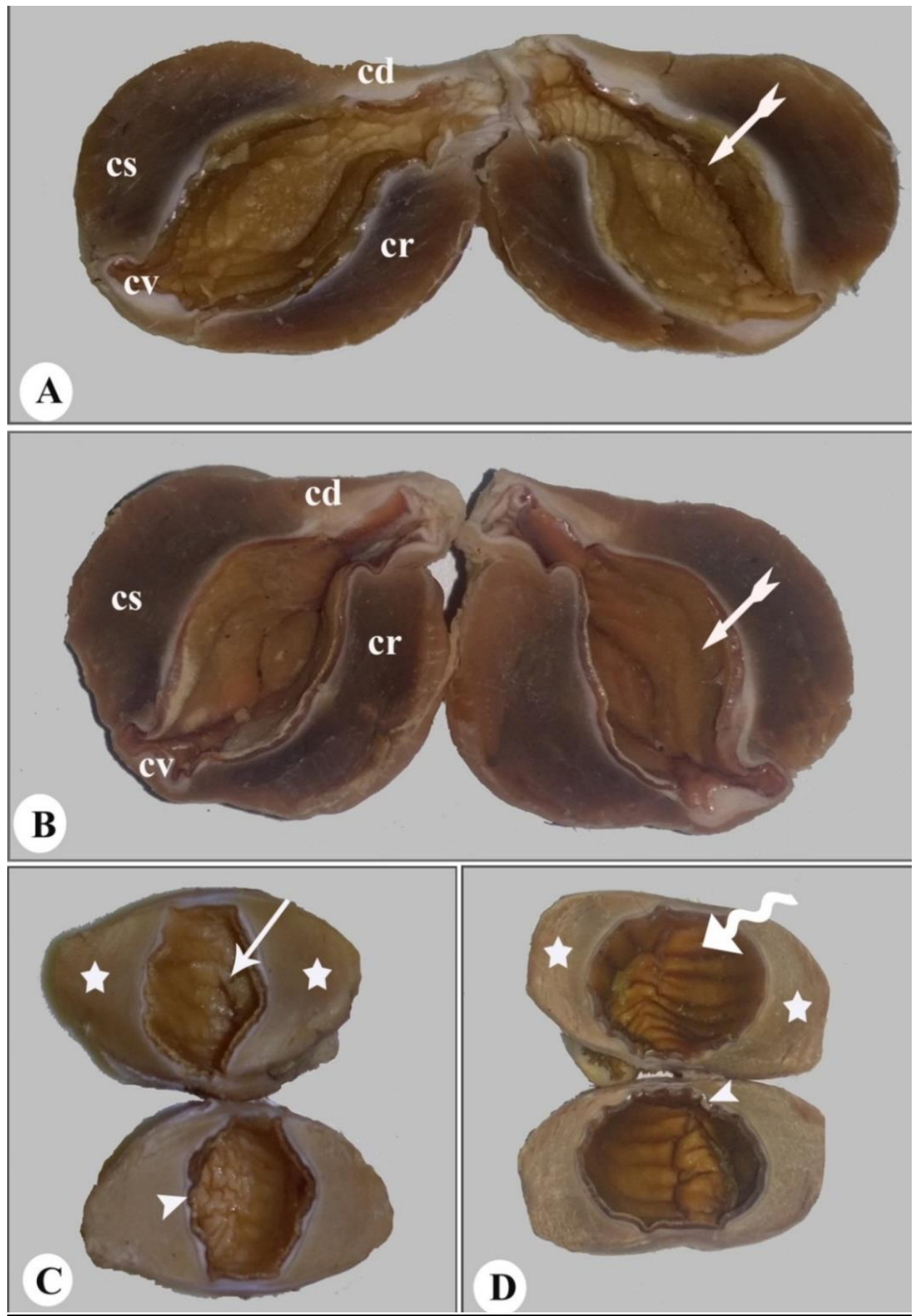

Fig. 2: Photographs of the interior of the gizzard after sectioning through the muscles; (A) \& (B) midway sections through thick muscles in dorsoventral plane parallel to the tendinous center and (C) \& (D) sections through thick muscles and tendinous center in dorsoventral plane of laughing dove and rock pigeon respectively. Note, caudodorsal (cs), cranioventral (cr) thick muscles and craniodorsal (cd) and caudoventral (cv) thin muscles, S shaped gizzard lumen (barbed arrow), rectangular shaped (arrow) and elliptical shaped (twisted arrow) gizzard lumen surrounded in both sides by semi ellipsoid thick muscles in both sides (stars), margin of lumen (arrow head). 


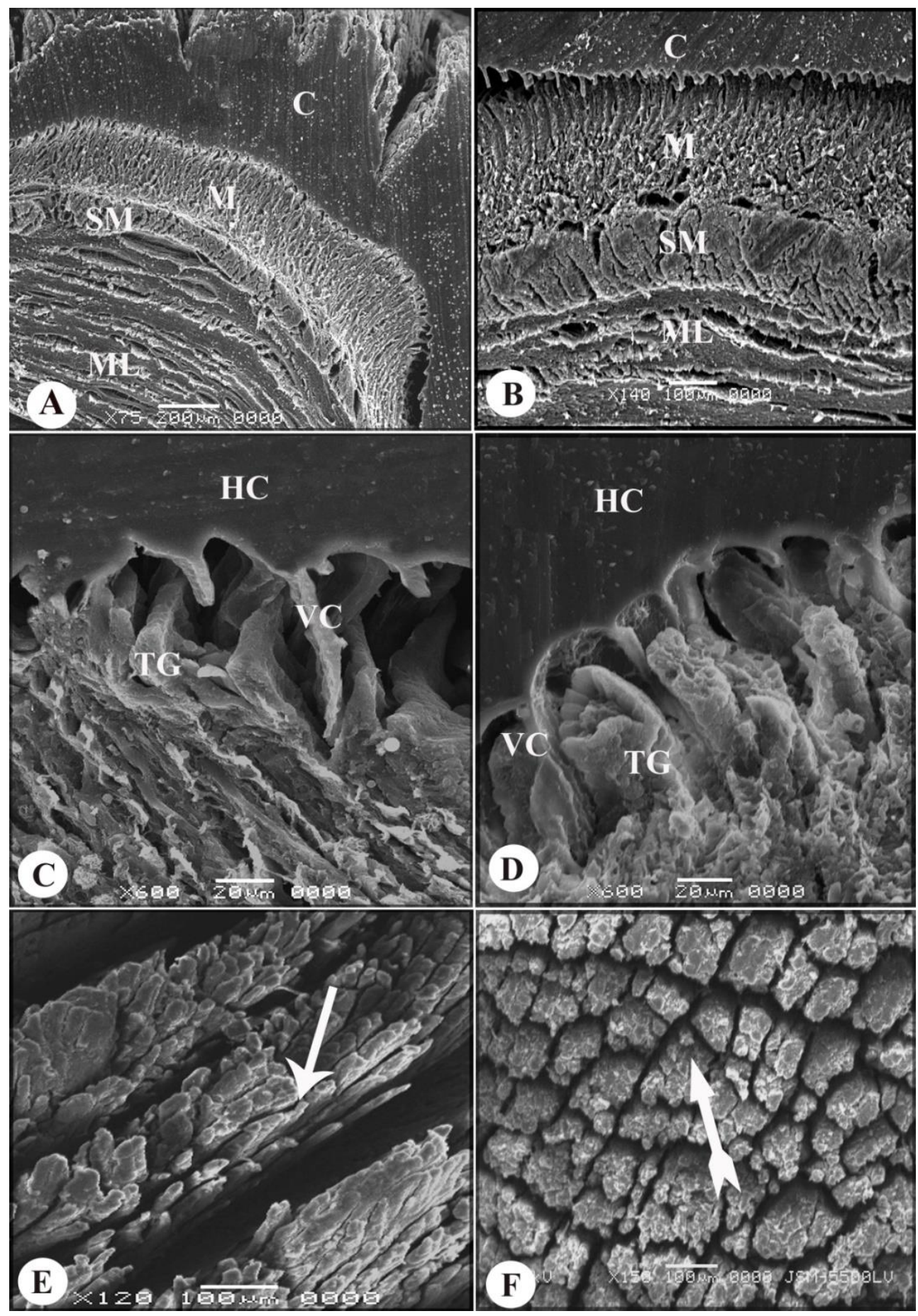

Fig.3: Scanning electron micrographs of the gizzard wall (A, C\&E) of laughing dove and (B, D\&F) of rock pigeon. Note, mucosa (M), submucosa (SM), muscular layer (ML), tubular glands (TG), vertical rods (VC) and horizontal matrix (HC) of the cuticle (C), The cutical folds resembled bundles of rods (arrow) and appeared as group of blunt projections (barbed arrow). 


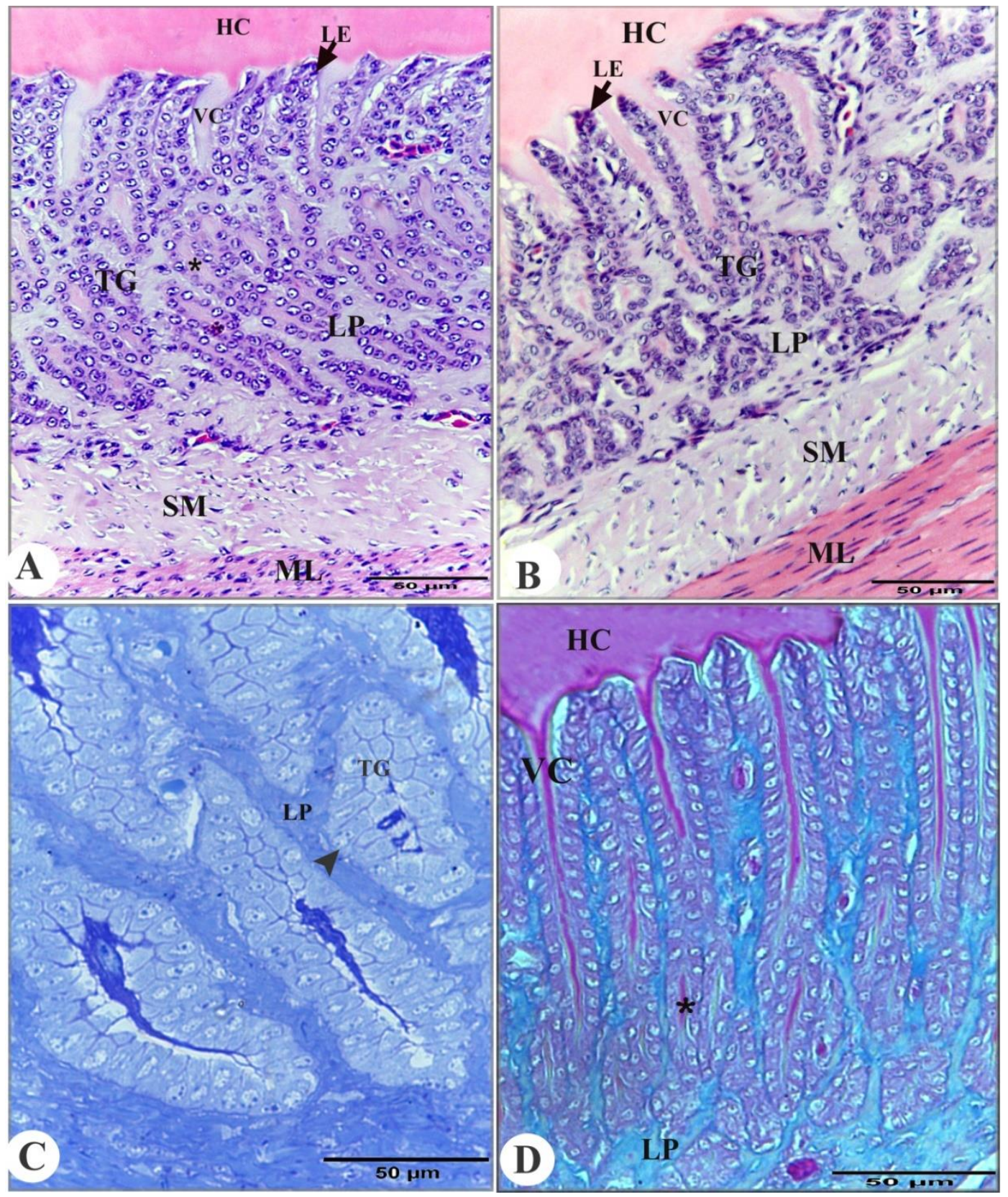

Fig. 4: Photomicrographs of the gizzard wall, paraffin sections stained with H\&E (A, B), Crossman's Trichrome (D), Semithin section stained with toluidine blue (C). Note, vertical rods (VC), horizontal matrix (HC) of the cutical layer, lamina epithelialis (LE), lamina propria (LP) occupied by tubular glands (TG) lining by columnar cells with large rounded or oval nuclei (arrow head), lumen of the glands (star), submucosa (SM) and muscular layer (ML).

\section{DISCUSSION}

The current results revealed that the gizzard extended from the level of the $5^{\text {th }}$ intercostal space to terminat $12.25 \pm 1.18,17.27 \pm 0.88 \mathrm{~mm}$ behind the last rib and $10.90 \pm 0.70,19.48 \pm 0.49 \mathrm{~mm}$ infront of the vent in $L D$ and $R P$ respectively. At this point, Hassouna (2001) in goose and turkey reported that the gizzard extended from the level of the $5^{\text {th }}$ rib to about 0.3 and $0.5 \mathrm{~cm}$ caudal to the caudal border of the last rib respectively. However, Madkour (2015) claimed that the gizzard in adult duck extended from the level of $4^{\text {th }}$ intercostal space to terminate 43.17 $\mathrm{mm}$ behind the last rib and $55.34 \mathrm{~mm}$ infront of the vent. In ostrich, the gizzard occupied the cranioventral part of the middle third of the body cavity from the $4^{\text {th }}$ to $7^{\text {th }}$ vertebral ribs (Mahdy, 2009). Statistical data revealed that the gizzard length and width were 18.99 \pm 0.53 and

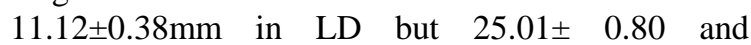
$15.41 \pm 0.17 \mathrm{~mm}$ in RP respectively. Hassan and Moussa (2012) registered that the length and width 
of the gizzard were 34 and $26 \mathrm{~mm}$ in pigeon respectively. Moreover, Madkour (2015) in duck recorded that gizzard was $60.54 \mathrm{~mm}$ long and 38.24 mm wide.

By SEM, the cuticle appeared as longitudinal folds resembled bundles of rods in LD and blunt projections in RP. Das et al. (2013) reported that the cutical layer composed of raised depositions. On the other hand, Ibrahim (1992) and Hassouna (2001) in meat-eating birds (owl, kestrel, heron, and jackdaw) described that the cuticle was more jell-like membrane and undivided. In falcon, the cuticula gastrica was restricted around the pyloric opening only (Abumandour, 2013). Langlois (2003) and Gussekloo (2006) stated that the cuticle acts as a grinding surface and protects the underlying mucosa from digestion by the acid and pepsin secreted by the proventriculus and mechanical action of food particles.

The histological results clarified that the lamina propria of the gizzard occupied by simple tubular glands, these results were in agreement with description of several authors in the other birds; Hassan and Moussa (2012) in pigeon and duck, Eidaroos et al. (2008) in geese and chickens, Mahdy (2009) in ostrich, and Hamdi et al. (2013) in the black winged kite. But these results disagreed with Olsen et al. (2002) in penguins who mentioned that no special glands were observed at the gizzard mucosa. According to the obtained literature and the results of this work, one type of cells lining the tubular glands which were columnar with rounded nuclei and basophilic cytoplasm. In this connection, Ahmed et al. (2011) described two types of cells in quail; the chief cells were of low columnar or cuboidal or flattened and the basal cells had rounded vesicular nuclei and deeply stained cytoplasm. Hassan and Moussa (2012) mentioned in duck and pigeon that the chief cells were cuboidal cells and the basal cells were a few, large and pale staining. On the other hand, in chicken, three main cell types in the tubular glands; chief, basal and argyrophil cells were observed by El-Shamy (1996). Some studies as in falcon (Abumandour, 2013) and in penguins (Olsen et al., 2002) reported that muscularis mucosa was presented which conflicted with the present results.

\section{ACKNOWLEDGMENT}

The authors are offered the great appreciation to the local owner of the laughing doves and rock pigeons in Qena who provide a sufficient number of the birds to finish this work

\section{REFERENCE}

Abumandour, M.M. (2013): Morphological studies of the stomach of falcon. Scientific Journal of Veterinary Advances. 2 (3): 30-40.

Adang, K.L.; Ezealor, A.U.; Abdu, P.A. and Yoriyo, K.P. (2008): Food habits of four sympatric columbids (Aves: Columbidae) in Zaria, Nigeria. Continental Journal of Biological Sciences. 1: 1-9.

Ahmed, Y.A.E.G.; Kamel, G. and Ahmad, A.A.E. (2011): Histomorphological studies on the stomach of the Japanese quail. Asian J. Poult. Sci. 5(2): 56-67.

Ali, S. and Ripley, S.D. (1981): Handbook of the Birds of India and Pakistan. New Delhi: Oxford University Press.

Bancroft, J.D.; Layton, C. and Suvarna, SK. (2013): Bancroft's Theory and Practice of Histological Techniques. Churchill Livingstone; 7 edition.

Crossman, G.A. (1937): A modification of Mallory's connective tissue stain with a discussion of principles involved. Anal. Rec. 69: 33-38.

Das, S.; Dhote, B.S.; Singh, G.K. and Mansi, P. (2013): Ultrastructural Studies on the Gizzard of Kadaknath Fowl. Indian Journal of Veterinary Anatomy. 25(1): 53-54.

Eidaroos, H.; Yoshimura, Y. and Helmy, S.A. (2008): Distribution of the ghrelin hormone producing cells in the gastrointestinal tract of some birds (immunohistochemical study). J. Vet. Anat. 1 (1): 14-21.

El-Shamy, S.A. (1996): Histological and histochemical studies of the digestive tract in fowl. Fac. Vet. Med., Ass. University. Ph. D.

Evans, H.E. (1996): Anatomy of the budgerigar and other birds. In Diseases of cage and aviary birds. edited by Rosskopf, W. J. and Woerpel, R. W., 3rd Ed. A Lea \& Febiger, Williams \& Wilkins A wavely company Philadelphia.

Gibbs, D.; Eustace, B. and John, C. (2010): Pigeons and Doves: A Guide to the Pigeons and Doves of the World. United Kingdom: Pica Press. ISBN 1-873403-60-7.

Gussekloo, S.W.S. (2006): Feeding structures in birds. In: Feeding in domestic vertebrates from structure to behaviour. CAB International, Wallingford, Oxford.

Hamdi, H.; El-Ghareeb, A.W.; Zaher, M. and Abu Amod, F. (2013): Anatomical, histological and histochemical adaptations of the avian alimentary canal to their food habits: IIElanus caeruleus International Journal of Scientific \& Engineering Research. 4: 13551364.

Harris, H.F. (1898): A new method of ripening hematoxylin. In: Mikroskopische Technik. Romeis (ed.), Oldenburg, München. 
Hassan, S.A. and Moussa, E.A. (2012): Gross and microscopic studies on the stomach of domestic duck (Anas platyrhynchos) and domestic pigeon (Columba livia domestica). J. Vet. Anat. 5 (2): 105-127

Hassouna, E.M.A. (2001): Some anatomical and morphometric studies on the esophagus and stomach of goose, turkey, sparrow, kestrel, hoopoe, owl and darter. Assuit Vet. Med. J. 44 (88): 21-46.

Heath, E. and Olusanya, S. (1985): Anatomy and Physiology of Tropical Livestock, Longman Group Ltd., London and New York.

Ibrahim, L.A. (1992): Topography and morphology of the esophagus and stomach in fowl, duck, pigeon, dove, quail, heron and jackdaw. Assuit Vet. Med. J. 28(55): 13-34.

Langlois, I. (2003): The anatomy, physiology, and diseases of avian proventriculus and ventriculus. Vet. Clin. Anim. 6: 85-111.
Madkour, F.A. (2015): Morphological studies on the stomach of the post-hatching ducks. Fac. Vet. Med. , South Valley University. Ph.D.

Mahdy, E.A.A. (2009): Some anatomical studies on the stomach of ostrich (Struthio camelus). Fac. Vet. Med., Zagazig University. M. D.

McLelland, J. (1979): Digestive system: In Form and Function in Birds edited by King, A. S. and McLelland, J., Academic Press Inc. Ltd, London.

Olsen, M.A.; Myklebust, R.; Kaino, T.; Elbron, V.S. and Mathiesen, S. (2002): The gastrointestinal tract of adelie penguinsmorphology and function. Polar Boil. 25: 641-649.

Satheesan, S.M.; Rao, P. and Datye, H. (1990): Biometrics and food of some doves of the genus Streptopelia. Journal of the Bombay Natural History Society. 87: 452-453.

\section{التشريح العيني والمجهري للقانصة في اليمام الضاحك والحمام الجبلي \\ فاطمه عباس محمد ملكور ، السبي عبل الحمبي محمد}

E-mail: madkour.fatma@yahoo.com; madkour.f@vet.svu.edu.eg Assiut University web-site: www.aun.edu.eg

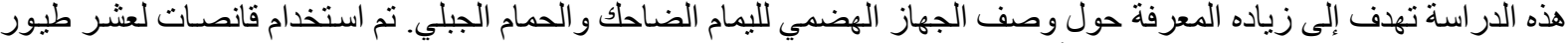

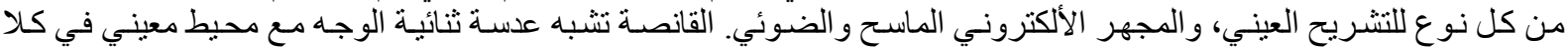

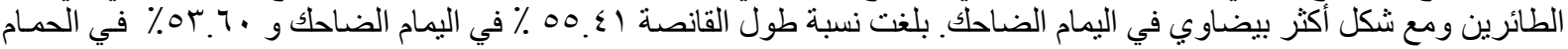

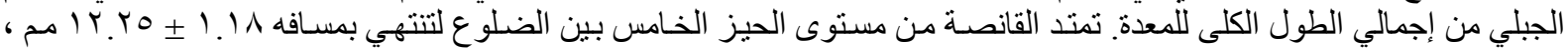

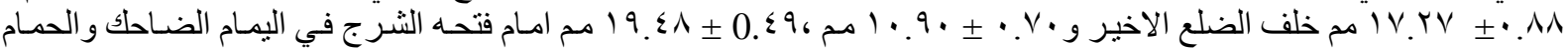

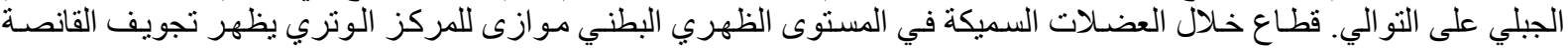

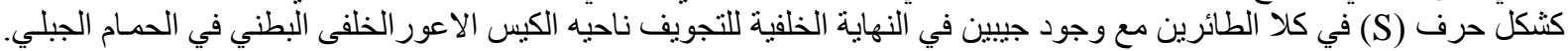

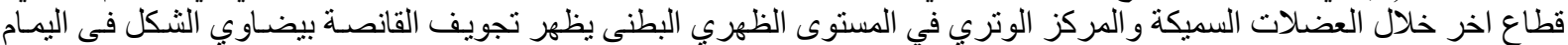

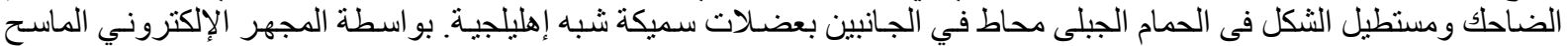

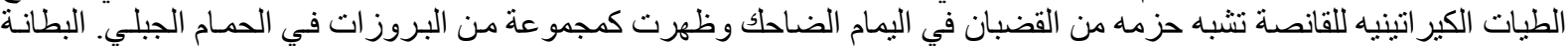

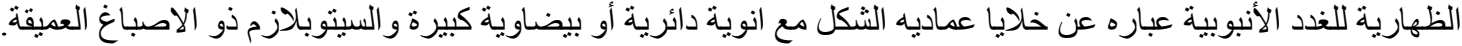

